\title{
Ectrodactilia em cão: relato de caso
}

[Ectrodactyly in dog: case report]

\author{
M.P. Ferreira ${ }^{1}$, M.M. Alievi ${ }^{2 *}$, C.A.C. Beck ${ }^{2}$, J. Voll' ${ }^{1}$, M.S. Muccillo ${ }^{1}$, C. Gomes ${ }^{1}$ \\ ${ }^{1}$ Hospital de Clínicas Veterinárias - UFRGS - Porto Alegre, RS \\ ${ }^{2}$ Faculdade de Veterinária - UFRGS \\ Av. Bento Gonçalves, 9090 \\ 91540-000 - Porto Alegre, RS
}

\begin{abstract}
RESUMO
Descreve-se um caso de ectrodactilia em um cão, sem raça definida e dois meses de idade. No exame clínico e radiográfico, foi verificada a separação óssea e de tecidos moles entre o segundo e o terceiro dígitos, estendendo-se proximalmente até a região distal do rádio e da ulna, e luxação do cotovelo ipsilateral. O animal foi submetido a procedimento cirúrgico para redução da luxação do cotovelo e reaproximação óssea e dos tecidos moles. Após 16 meses da cirurgia, o animal apresentava uso parcial do membro.
\end{abstract}

Palavras-chave: cão, ectrodactilia, malformação congênita, luxação de cotovelo

\begin{abstract}
A case of ectrodactyly is described in a 2-month-old male mixed Terrier dog. The defect was a complete osseous and soft tissue separation extending from between digits 2 and 3 proximally to the level of the radius and ulna. Radiography revealed elbow luxation. Treatment consisted of surgical reduction of elbow luxation and soft tissue reconstruction. Sixteen months after surgery, the dog was intermittent nonweight-bearing lameness.
\end{abstract}

Keywords: dog, ectrodactyly, congenital malformation, elbow luxation

\section{INTRODUÇÃO}

Em medicina veterinária, utiliza-se o termo ectrodactilia para designar aqueles casos em que há separação dos tecidos moles e ósseos na região distal dos membros torácicos (Barrand, 2004). Essa alteração, também conhecida como doença da mão fissurada, deformidade em garra de lagosta, oligodactilia e hipodactilia, é uma falha na fusão dos precursores embrionários nos ossos do membro torácico (Carrig et al., 1981). Nessa afecção, há separação das porções medial e lateral do membro, podendo ocorrer abaixo dos ossos metacarpianos e estender-se até o rádio e a ulna (Carrig et al., 1981; Johnson, 1995). Os tecidos moles acompanham a separação óssea (Johnson, 1995; Oliveira e Artoni, 2002) e a anomalia pode estar acompanhada de aplasia e hipoplasia de vários ossos carpianos e metacarpianos, polidactilia, fusão de metacarpianos e luxação de cotovelo (Carrig et al., 1981; Jubb et al., 1988; Oliveira e Artoni, 2002).

A ectrodactilia ocorre em cães (Carrig et al., 1981; Pratschke, 1996; Innes et al., 2001; Barrand, 2004), gatos (Schneck, 1974), pássaros, homens, macacos, ratos (Cooper et al., 1990) e bovinos (Montgomery et al., 1989). Não há predisposição sexual ou racial relacionada à ectrodactilia e normalmente ela se desenvolve de forma unilateral, não tendo predisposição entre os membros (Carrig et al., 1981).

O presente relato teve por objetivo descrever um caso de ectrodactilia em um cão.

Recebido em 17 de março de 2006

Aceito em 23 de março de 2007

*Autor para correspondência (corresponding author)

E-mail: marcelo.alievi@ufrgs.br 


\section{CASUística}

Um cão sem raça definida, macho, com dois meses de idade foi atendido no Hospital de Clínicas Veterinárias da Universidade Federal do Rio Grande do Sul com histórico de claudicação intensa e deformidade congênita no membro torácico esquerdo (Fig. 1). No exame clínico, foi verificada separação óssea e de tecidos moles entre o segundo e o terceiro dígitos, estendendo-se proximalmente até a região distal do rádio e da ulna, associada à contratura dos músculos flexores do antebraço, encurtamento do membro, dor e crepitação durante a flexão e a extensão do cotovelo.

O paciente foi sedado e encaminhado para exame radiográfico nas projeções antero-posterior e mediolateral do membro afetado, onde foi constatada a separação dos tecidos moles e ósseos, caracterizando, dessa forma, a malformação congênita. Além dessa alteração, foi verificada luxação da articulação umeroradioulnar (Fig. 2). Após discussão do caso com o proprietário, decidiu-se pelo tratamento cirúrgico reconstrutivo do membro.

Após jejum de oito horas, o paciente recebeu, como medicação pré-anestésica, meperidina ${ }^{1}(2 \mathrm{mg} / \mathrm{kg}$, IM) e acepromazina ${ }^{2}(0,1 \mathrm{mg} / \mathrm{kg}, \mathrm{IM})$. Passados 15 minutos, a indução anestésica foi efetuada com propofol $^{3}(4 \mathrm{mg} / \mathrm{kg}$, IV), e a anestesia geral foi mantida com isoflurano ${ }^{4}$. No procedimento cirúrgico, fez-se a aproximação dos ossos mediante síntese dos tecidos subcutâneo e pele, com pontos isolados simples, utilizando fio mononáilon 2-0, e redução da luxação do cotovelo com um pino transarticular e fio de aço. No pós-operatório, o animal recebeu cloridrato de tramadol $^{5}$ (2 $\mathrm{mg} / \mathrm{kg} / \mathrm{TID})$ por dois dias e meloxican ${ }^{6}(0,2$ $\mathrm{mg} / \mathrm{kg} / \mathrm{SID})$ durante sete dias. Aplicou-se uma bandagem de Robert-Jones modificada, trocada semanalmente e mantida por três semanas. $\mathrm{Na}$ última troca, foi removido, cirurgicamente, o pino transarticular, após o que, o animal foi liberado para uso livre do membro.

Passados 16 meses do procedimento cirúrgico, o animal apresentou uso parcial do membro, com apoio eventual durante o caminhar, mas apoio

${ }^{1}$ Dolosal - Cristália - Porto Alegre, RS

${ }^{2}$ Acepran - Jofadel - Porto Alegre, RS

${ }^{3}$ Provive - Clarís - USA

${ }^{4}$ Forane - Abbott - São Paulo, SP

${ }^{5}$ Dorless - União Química Farmacêutica Nacional - São

Paulo, SP

${ }^{6}$ Maxican - Ouro Fino - São Paulo, SP freqüente ao correr e brincar. No exame radiográfico verificou-se subluxação do cotovelo, encurtamento do rádio e ulna, agenesia e hipogenesia de alguns ossos cárpicos (Fig. 3).

\section{DISCUSSÃO}

Em gatos a ectrodactilia está associada à herdabilidade de um gene autossômico dominante, porém, em cães, essa relação ainda não foi estabelecida. Em humanos, ela pode estar associada a outras deformidades congênitas como displasia ectodérmica e fenda palatina, mas na espécie canina não foi relacionada outra alteração congênita (Innes et al., 2001). No caso relatado, não foram verificadas outras alterações congênitas, observando-se o desenvolvimento adequado do animal, sem qualquer retardo ou alteração no crescimento.

Apesar de ser possível diagnosticar a ectrodactilia mediante exame clínico, o exame radiográfico foi fundamental para a confirmação da luxação do cotovelo e para identificar outras alterações ósseas, como agenesia e hipoplasia dos ossos cárpicos. Essas alterações podem influenciar na escolha da terapia, pois, quando não há malformações ósseas muito extensas, pode-se realizar apenas a aproximação dos tecidos moles e ósseos. Entretanto, nos casos mais graves, pode ser necessária a realização da artrodese ou da amputação do membro (Frey e Williams, 1995), sendo a artrodese do carpo ou do metacarpo o procedimento mais adotado (Innes et al., 2001).

Neste relato não foi possível diagnosticar todas as alterações ósseas em um primeiro momento devido à idade de diagnóstico da ectrodactilia, já que determinadas alterações ósseas, como hipoplasia de ossos carpianos, só podem ser radiograficamente identificadas com a completa ossificação das estruturas.

Assim, como relatado por Carrig et al. (1981), em seis casos, e por Innes et al. (2001), em um caso, o presente estudo identificou luxação umeroradioulnar ipsilateral. Segundo Barrand (2004), essa alteração parece ser conseqüência da ectrodactilia e não a causa dela, fato constatado por não haver relatos dessa doença em cães com predisposição racial para luxação congênita de cotovelo como o Pequinês, Poodle Toy, Pug, Chiuaua, Pinscher, Daschund e Yorkshire. 


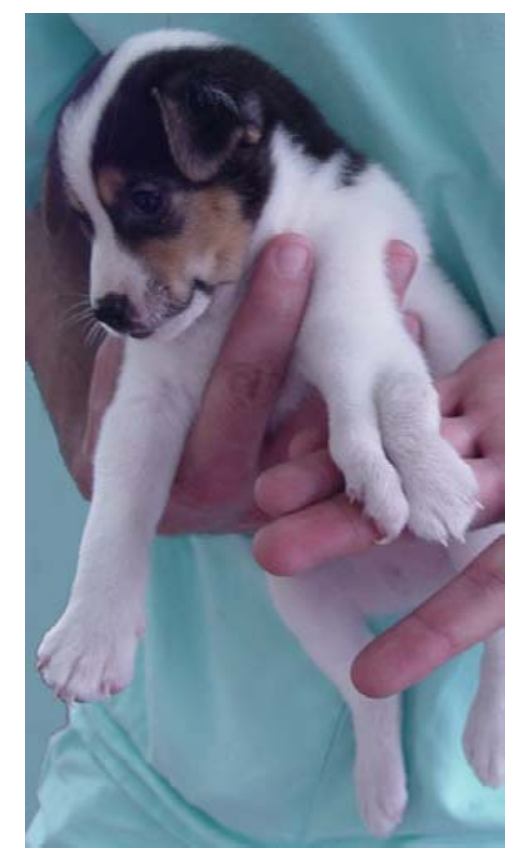

Figura 1. Deformidade congênita no membro torácico esquerdo.

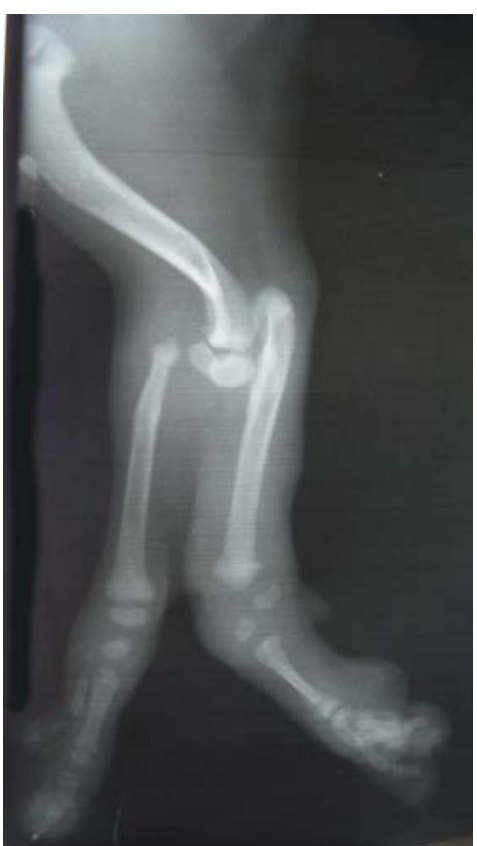

Figura 2. Exame radiográfico pré-operatório do membro afetado.

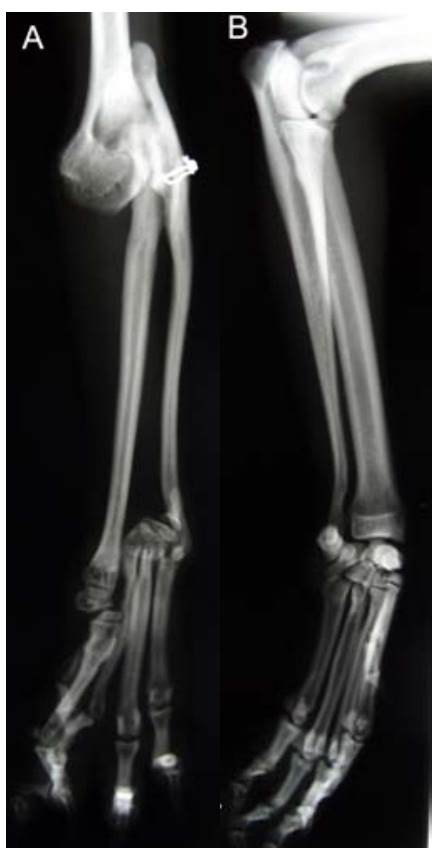

Figura 3. Exame radiográfico dos membros anteriores: (A) membro esquerdo e (B) membro direito - animal com 18 meses de idade.
Neste relato, a separação óssea e de tecidos moles estendeu-se proximalmente até a região distal do rádio e ulna, sendo considerado um achado pouco freqüente. Com base nos estudos de Carrig et al. (1981) e de Innes et al. (2001), os quais avaliaram um total de 19 casos de ectrodactilia em cães, a separação de tecidos moles e ósseos envolve na maioria das vezes apenas os metacarpianos, sendo a separação do rádio e ulna ou do carpo menos freqüente.

Carrig et al. (1981), em estudo de 15 membros de 14 cães com ectrodactilia, relataram que as principais alterações foram hipoplasia óssea, contratura dos tecidos moles e fusão óssea (sindactilia). Neste relato, o animal apresentou contratura dos dígitos e encurtamento da ulna e não se verificou fusão de ossos.

A terapia realizada neste relato está de acordo com a descrita por Johnson (1995) e Barrand (2004) e baseou-se na presença de estrutura óssea radiograficamente pouco alterada e na possibilidade de recuperação estética e funcional do membro. Apesar de não ter sido obtido sucesso absoluto na funcionalidade do membro, fato justificado pela diferença de cinco centímetros entre o membro afetado e o contralateral, esteticamente o resultado foi melhor que a amputação. Isso justifica a manutenção do membro apesar de este não ser plenamente funcional. A osteogênese por distração seria uma opção para a correção da disparidade de tamanho entre os membros ou para corrigir diferenças de comprimento entre o rádio e a ulna, como foi utilizada por Innes et al. (2001) em dois casos.

Foi indicado orquiectomia baseando-se na recomendação de Montgomery et al. (1989) e Frey e Williams (1995), os quais justificam tal procedimento devido ao provável caráter hereditário da afecção.

\section{REFERÊNCIAS BIBLIOGRÁFICAS}

BARRAND, K.R. Ectrodactyly in a West Highland White Terrier. J. Small Anim. Pract., v.45, p.315-318, 2004.

CARRIG, C.B.; WORTMAN, J.A.; MORRIS, E.L. et al. Ectrodactyly (split-hand deformity) in the dog. Vet. Radiol., v.22, p.123-144, 1981. 
COOPER, J.E.; PURTON, P.; POSWILLO, D.E. A lobster claw abnormality in the common marmoset (Callithrix jacchus). Lab. Anim., v.24, p.151-155, 1990.

FREY, M.; WILLIAMS, J. What is your diagnosis? (Ectrodactyly in a Chow Chow dog). J. Am. Vet. Med. Assoc., v.206, p.619-620, 1995.

INNES， J.F.; McKEE，W.M.; MITCHELL, R.A.S. et al. Surgical reconstruction of ectrodactyly deformity in four dogs. Vet. Comp. Orthop. Traumatol., v.14, p.201-209, 2001.

JOHNSON, A.L. Growth deformities. In: OLMSTEAD, M.L. (Ed). Small animal orthopedics. 1.ed. St. Louis: Mosby, 1995. p.293-310.
JUBB, K.V.F.; KENNEDY, P.C.; PALMER, N. (Eds). Patología de los animales domésticos. 3.ed. Uruguay: Hemisfério Sur, 1988. p.1-167.

MONTGOMERY, R.D.; MILTON, J.L.; MANSFIELD, P.D. et al. What is your diagnosis? (Ectrodactyly in a dog). J. Am. Vet. Med. Assoc., v.194, p.120-121, 1989.

OLIVEIRA, D.; ARTONI, S.M.B. Ectrodactilia em cão (Canis domestica). Cienc. Rural, v.32, p.1063-1065, 2002.

PRATSCHKE, K. A case of ectrodactyly in a dog. Ir. Vet. J., v.49, p.412-413, 1996.

SCHNECK, G.W. Two cases of congenital malformation (peromelus ascelus and ectrodactyly) in cats. Vet. Med. Small Anim. Clin., v.69, p.1025-1026, 1974. 